\title{
Kekerasan Seksual di Penjara Syariat Melalui @JurnalisKomik
}

\author{
Deviana Fauziyyah Nabilah*, Askurifa'I Baksin \\ Fakultas Ilmu Komunikasi, Universitas Islam Bandung, Indonesia \\ *deviana_fn@yahoo.com, askurifai@unisba.ac.id
}

\begin{abstract}
Today there are various new genres in the world of journalism, one of which is comic journalists who marry journalistic writing with comic illustrations. Like the report titled "Sexual Violence in Sharia Prison" that occurred in Langsa Aceh, through its comic @ journaliscomics conveys messages or signs contained in the picture, this indicates that a comic illustration contains many signs that have meaning, purpose, and purpose.Therefore the purpose of this research is to find out (1) the meaning of the denotation of the news content "Sexual Violence in Sharia Prison" which is packaged through comic journalism in Instagram @ jurnaliskomik social media (2) the meaning of the connotation of news content "Sexual Violence in Sharia Prison" which is packaged through comic journalism on social media Instagram @ jurnaliskomik (3) knowing the myth in the news content "Sexual Violence in Sharia Prison" which is packaged through comic journalism on Instagram @ jurnaliskomik social media.The study uses qualitative research methods with Roland Barthes's semiotic analysis approach through observation, interview and literature study data collection techniques. The object of the research is the news content in the form of comic panels in Instagram @ jurnaliskomik which is manifested a "sexual Violence in Sharia Prison" The supporting informants to be a comparison of this research are comic artists from the JurnalisKomik. The results of this study are as follows: (1) The meaning of denotation in the news "Sexual Violence imprisoned by Shari'a" as quite striking contrast coloring and facial features in comic characters show various expressions according to the context that is happening, so it is easily digested by its readers (2) the meaning of the connotation in the news "Sexual Violence in Sharia Prison" shows the existence of sad feelings because the incident occurred in Langsa City, Aceh which has an image of a region with people who are religious and run Islamic law (3) Myth in the news"Sexual Violence in Sharia Prison" illustrates women's feelings are weak according to Eastern culture and there is no power and effort to defend themselves.
\end{abstract}

\section{Keywords: Comic Journalism, Instagram account @ jurnaliskomik, Sexual Assault, Semiotic}

\begin{abstract}
Abstrak. Dewasa ini terdapat berbagai genre baru di dunia jurnalistik, salah satunya jurnalis komik dengan mengawinkan penulisan jurnalistik dengan ilustrasi komik. Seperti pemberitaan berjudul "Kekerasan Seksual di Penjara Syariat" yang terjadi di Langsa Aceh, Melalui komiknya @jurnaliskomik menyampaikan pesanpesan atau tanda-tanda yang terkandung di dalam gambarnya, hal tersebut menandakan bahwa sebuah ilustrasi komik mengandung banyak tanda yang memiliki makna, maksud, dan tujuan. Maka dari itu tujuan Penelitian ini adalah untuk mengetahui (1) makna denotasi konten berita "Kekerasan Seksual di Penjara Syariat" yang dikemas melalui jurnalisme komik dalam media sosial Instagram @jurnaliskomik (2) makna konotasi konten berita "Kekerasan Seksual di Penjara Syariat" yang dikemas melalui jurnalisme komik dalam media sosial Instagram @jurnaliskomik (3) mengetahui mitos dalam konten berita "Kekerasan Seksual di Penjara Syariat" yang dikemas melalui jurnalisme komik dalam media sosial Instagram @jurnaliskomik. Penelitian menggunakan metode penelitian kualitatif dengan pendekatan analisis semiotic Roland Barthes melalui teknik pengumpulan data observasi, wawancara, studi pustaka. Untuk objek penelitiannya adalah konten berita berupa panel-panel komik dalam Instagram @jurnaliskomik yang berujudul "Kekerasan Seksual Di Penjara Syariat" Adapun narasumber pendukung untuk menjadi perbandingan penelitian ini yaitu komikus dari JurnalisKomik. Hasil dari penelitian ini sebagai berikut: (1) Makna denotasi dalam berita "Kekerasan Seksual dipenjara Syariat" memiliki kontras pewarnaan cukup mencolok dan detail raut wajah dalam karakter komik menunjukkan ekspresi yang beragam sesuai dengan konteks yang sedang terjadi, sehingga mudah dicerna oleh pembacanya (2) makna konotasi dalam berita "Kekerasan Seksual dipenjara Syariat" menujukkan adanya perasaan miris karena kejadian tersebut terjadi di Kota Langsa, Aceh yang memiliki image wilayah dengan penduduk yang taat beragama dan menjalankan syariat Islam (3) Mitos dalam berita "Kekerasan Seksual dipenjara Syariat" menggambarkan perasaan wanita yang lemah menurut kebudayaan Timur dan tiada daya sertaupaya untuk membela diri.
\end{abstract}

Kata Kunci: Jurnalisme komik, @jurnaliskomik, Kekerasan Seksual, Analisis Semiotik 


\section{A. Pendahuluan}

Munculnya genre baru dalam jurnalistik menjadi sebuah daya Tarik bagi masyarakat untuk memahami sebuah permasalahan yang terjadi. Sebut saja jurnalisme komik, yang diintrodusir pertama kali oleh Joe Sacco pada tahun 90-an yang mengemas praktik jurnalisme komik

Menurut Littlejohn (dalam Sobur, 2004:15) tanda - tanda adalah basis dari seluruh komunikasi. Manusia dengan perantaraan tanda - tanda, dapat melakukan komunikasi dengan sesamanya. Untuk mengkaji komik, perlu tafsir tanda. Komik menjadi medium yang efektif untuk menyampaikan berita dalam memvisualisasikan tulisan - tulisan yang panjang agar mudah dapat lebih dipahami. Jurnalisme komik memungkinkan perkawinan antara penulisan jurnalistik dan ilustrasi komik dalam proses pembuatan berita.

Di Indonesia produk jurnalistik berbalut komik sudah memiliki praktisinya sendiri, salah satunya adalah pada lini masa Instagram @jurnaliskomik. Dalam perjalanannya kemunculan@jurnaliskomik menjadi pembeda dalam sebuah pengemasan informasi, yang menjadi pembeda dalam hal ini adalah bagaimana sebuah berita disuguhkan dengan ilustrasi komik bermuatan narasi jurnalistik.

Akun @jurnaliskomik mengulas kasus pelecehan seksual yang terjadi 9 tahun lalu di Langsa, Aceh melibatkan tiga oknum polisi yang memerkosa tahanan wanita. Kasus ini terkuak saat korban menangis terus di dalam ruang tahanan. Kasus ini mendapat perhatian dari publik atas ketidakadilan dirasakan oleh. korban. Yang mendapat perhatian adalah bagaimana sungguh tragisnya peristiwa memilukan ini. Hukum syariat yang diberlakukan di Aceh seakan tidak terjalankan, karena hukuman tersebut tidak berlaku bagi tiga oknum poisi syariat tersebut.

Dalam hal ini, @jurnaliskomik memberikan gambaran ilustrasi terkait berita Penjara Syariat yang menarik dengan menggambarkan bagaimana proses terjadinya kekerasan seksual yang dilakukan oleh tiga oknum polisi kepada korban tanpa melanggar ketentuan jurnalisme. Rekontruksi peristiwa hanya tergambar dalam kepala masing - masing pembaca, sehingga pembaca memiliki referensi sendiri dalam membayangkan peristiwa.

Melalui komiknya@jurnaliskomik menyampaikan pesan - pesan atau tanda - tanda yang terkandung di dalam gambarnya, hal tersebut menandakan bahwa sebuah ilustrasi komik mengandung banyak tanda yang memiliki makna, maksud, dan tujuan. Contohnya dalam ekspresi muka, gelagat tubuh, perwarnaan dalam gambar, hingga font komik. Karena itu peneliti menggunakan metode semiotik untuk mengetahui makna dan isi pesan apa yang sebenarnya terdapat di dalam sebuah tanda - tanda dan gambar - gambar dalam ilustrasi komik "Kekerasan Di Penjara Syariat" yang dibuat oleh @jurnaliskomik Berdasarkan pendahuluan di atas, maka memunculkan pertanyaan penelitian sebagai berikut: (1) Bagaimana makna denotasi dalam konten berita "Kekerasan Seksual di Penjara Syariat" yang dikemas melalui jurnalisme komik dalam media sosial Instagram @jurnaliskomik?; (2) Bagaimana makna konotasi dalam konten berita "kekerasan Seksual di Penjara Syariat" yang dikemas melalui jurnalisme komik dalam media sosial Instagram @jurnaliskomik?; (3) Bagaimana mitos dalam konten berita "kekerasan Seksual di Penjara Syariat" yang dikemas melalui jurnalisme komik dalam media sosial Instagram @jurnaliskomik?

Selanjutnya, tujuan pada penelitian ini adalah:

1. Untuk mengetahui makna denotasi konten berita "Kekerasan Seksual di Penjara Syariat" yang dikemas melalui jurnalisme komik dalam media sosial Instagram @ jurnaliskomik

2. Untuk mengetahui makna konotasi konten berita "Kekerasan Seksual di Penjara Syariat" yang dikemas melalui jurnalisme komik dalam media sosial Instagram @ jurnaliskomik

3. Untuk mengetahui mitos dalam konten berita "Kekerasan Seksual di Penjara Syariat" yang dikemas melalui jurnalisme komik dalam media sosial Instagram @jurnaliskomik

\section{B. Landasan Teori}

Dalam penelitian ini, penulis menggunakan Teori Paradigma naratif yang dikemukakan oleh Wlter Fisher ini menyebutkan pada hakekatnya manusia itu adalah makhluk pencerita, maka dari itu segala bentuk yang bersifat informasi yang disebarkan dengan cara deskriptif atau penceritaan akan lebih efektif. Robert roeland berpendapat bahwa ide yang ada pada masyarakat 
pada dasarnya pencerita itu telah diadopsi oleh banyak mata pelajaran yang berbeda-beda termasuk sejarah, biologi, antropologi, sosiologi, dan teologi. Pelajaran komunikasi juga dipengaruhi oleh ketertarikan dalam narasi.

Fisher menjelaskan pergeseran paradigma dengan menceritakan kembali sejarah paradigma yang mengarahkan pemikiran barat. Fisher melihat bahwa logos pada awalnya adalah sebuah kombinasi konsep termasuk kisah, wacana, dan pemikiran.

Dengan kata lain, kita lebih dapat terbujuk oleh sebuah cerita yang bagus dibandingkan dengan argument yang baik. Dalam teori ini Fisher menyatakan 5 asumsi, yakni:

1. Manusia pada dasarnya adalah makhluk pencerita.

2. Keputusan mengenai harga dari sebuah cerita didasarkan pada "pertimbangan yang sehat"

3. Pertimbangan yang sehat ditentukan oleh sejarah, biografi, budaya dan karakter

4. Rasionalitas didasarkan pada penilaian orang mengenai konsistensi dan kebenaran sebuah cerita.

5. Seseorang mengalami dunia yang diisi dengan cerita, dan kita harus memilih cerita yang ada.

\section{Hasil Penelitian dan Pembahasan}

Makna denotasi dalam konten berita "Kekerasan Seksual di Penjara Syariat" pada akun @ jurnaliskomik

Dalam panel pertama memperlihatkan korban kekerasan seksual seorang perempuan berhijab diapit oleh dua petugas Wilayatul Hibah (polisi syariah) dengan muka yang tertunduk sedih. Panel gambar kedua di bawahnya menunjukkan dengan jelas sosok korban duduk berdua bersama laki-laki yang diduga kekasihnya di suatu hutan, sehingga dapat dipahami bahwa kedua pasangan tersebut telah melakukan khalwat. Panel ketiga di bawah menunjukkan adanya gambar sosok wajah petugas polisi syariat yang tersenyum simpul sebagai petunjuk adanya alur cerita yang mulai bergeser dari tertangkapnya sepasang kekasih yang melakukan khalwat kepada isi dari judul komik itu sendiri yaitu "Kekerasan Seksual di Penjara Syariat". Panel komik keempat secara denotasi memberikan gambaran wajah ketiga sosok polisi syariat yang telah melakukan pemerkosaan terhadap tersangka permpuan sebagaimana yang diceritakan pada gambar ketiga panel komik ketiga. Gambar pada panel Komik ke lima mendeskripsikan bahwa korban dengan teman prianya yang ditangkap dan dibawa ke markas polisi syariat dan dipertegas melalui tulisan yang mempertegas alur krinologis kejadian bahwa kedua pasangan terebut akan dilepaskan oleh Polisi Syariat. Gambar pada panel ke enam ditinjau dari perspektif denotasi secara tegas menggambarkan tangan tersangka wanita dipegang erat oleh tangan Polisi Syariat dan dilengkapi gambar tersangka wanita yang menutupi mukanya dengan tangan yang mendeskripsikan kondisi sedang menangis. Gambar pada panel komik terakhir secara denotasi menunjukan vonis hakim kepada tersangka dengan merujuk pada gambar sebuah palu pengadilan yang akan diketuk dan gambar sosok hakim yang sedang menbacakan keputusan pengadilan

\section{Makna konotasi dalam konten berita "Kekerasan Seksual di Penjara Syariat" pada akun @jurnaliskomik}

Panel Komik pertama yang menggambarkan Wajah korban yang digambarkan dengan posisi tertunduk menandakan perasaan korban dengan pasangannya yang diduga melakukan khalwat (berduaan di tempat umum) yang merasa tertekan dan merasa malu dengan adanya penangkap kepadanya. Kemudian pada gambar selanjutnya yang menunjuukan gambaan pakaian wanita wilayatuh hibah $(\mathrm{WH})$ atau Polisi Syariah Wanita dengan memakai kerudung, menandakan betapa kuatnya unsur syariat Islam di Langsa, Aceh. Membuat masyarakat mengharapkan mendapatkan perlindungan yang aman dan keadilan sebagaimana inti dari ajaran Islam. Alur selanjutnya dalam panel komik "Kejahatan Seksual di Penjara Syariat" adalah gambar wajah dengan mata yang sayu menunjukkan sikap penyesalan dan pasrah dari sosok tersebut. Konotasi dari mata yang sayu didentikan dengan penyesalan dan pasrah dari sesorang perempuan. Pada 
gambar panel yang ketiga, terdapat gambaran adanya percakapan antara wanita yang ditahan Polisi Syariat tersebut dengan salah satu petugas. Dalam gambar tersebut, secara konotasi penempatan korban yang lebih rendah dibandingkan dengan posisi polisi syairat, menyiratkan derajat sosial dari keduanya. Gambar pada panel selanjutnya menerangkan adanya peristiwa yang menjadi inti dari komik tersebut yaitu telah terjadi pelecehan seksual yang dilakukan oknum polisi syariat terhadap wanita yang ditahan karena terduga berbuat khalwat. Selanjutnya gambar pada panel komik terakhir diawali oleg gambar palu siding yang akan diketok hakim. Dari sisi konotasi, gambar palu tersebut menggambarkan vonis yang telah disahkan oleh hakim.

\section{Makna mitos dalam konten berita "Kekerasan Seksual di Penjara Syariat" pada akun @jurnaliskomik}

Mitos dalam teori Barthes adalah suatu bentuk pesan atau tuturan yang harus diyakini kebenarannya tetapi tidak dapat dibuktikan, tetapi Dalam mitos tersebut terdapat ideologi yang disampaikan. Dalam hal ini, pengangkatan judul komik dengan tema "Kekerasan Seksual di Penjara Syariat" menunjukkan bahwa akun @jurnalkomik ingin menyampaikan pesan adanya kejadian yang miris yaitu kekerasan seksual yang merupakan perbuatan melanggar hukum justru terjadi di kantor pengak hukum itu sendiri yaitu Markas Polisi Syariah Kota Langsa Provinsi NAD. Selain itu, kemirisan lain dalam peristiwa yang digambarkan melalui bentuk komik oleh akun@jurnaliskomik yaitu kejadian tersebut terjadi di wilayah yang menerapkan syariah Islam. Dengan demikian, secara mitos penulis menganalisa bahwa inti ide yang disampaikan oleh akun @jurnaliskomik adalah kemirisan dan peristiwa prihatin yang terjadi di salah satu Provinsi di Indonesia yaitu Nangroe Aceh Darussalam (NAD) yang menerpakan otonomi pemberlakuan syariah Islam dan identik dengan kesucian agama Islam.

\section{Kesimpulan}

Berdasarkan hasil penelitian dan analisa pembahasan mengenai konten komik tentang berita dan kejadian "Kekerasan Seksual di Penjara Syariat" yang diup-load oleh akun @ Jurnaliskomik serta berdasarkan pertanyaan penelitian, maka kesimpulan dari penelitian ini adalah sebagai berikut:

1. Makna denotasi konten berita "Kekerasan Seksual di Penjara Syariat" yang dikemas melalui jurnalisme komik dalam media sosial Instagram @jurnaliskomik menunjukkan adanya gambar yang memiliki kontras pewarnaan cukup mencolok dan detail raut wajah dalam karakter komik menunjukkan ekspresi yang beragam sesuai dengan konteks yang sedang terjadi, sehingga mudah dicerna oleh pembacanya.

2. Makna konotasi konten berita "Kekerasan Seksual di Penjara Syariat" yang dikemas melalui jurnalisme komik dalam media sosial Instagram @jurnaliskomik menujukkan adanya perasaan miris karena kejadian tersebut terjadi di Kota Langsa, Aceh yang memiliki image wilayah dengan penduduk yang taat beragama dan menjalankan syariat Islam.

3. Mitos dalam konten berita "Kekerasan Seksual di Penjara Syariat" yang dikemas melalui jurnalisme komik dalam media sosial Instagram @jurnaliskomik menggambarkan perasaan wanita yang lemah menurut kebudayaan Timur dan tiada daya sertaupaya untuk membela diri ketika sosok wanita si korban di komik itu mengalami pelecehan seksual oleh oknum aparat Polisi Syariat.

\section{E. Saran}

\section{Saran Teoritis}

Peneliti menyarankan agar lebih banyak penelitian mengenai peliputan bergaya jurnalisme komik di media isu agar dapat menghasilkan data-data penungjang bagi penelitian selanjutnya.

\section{Saran Praktis}

Berdasarkan hasil penelitian dan kesimpulan yang telah diuraikan di atas, maka dalam hal ini penulis memberikan saran-saran sebagai berikut:

Agar riset mengenai tema jurnalistik perlu diperbanyak lagi mengingat media jurnalis 
mengalami perkembangan dan mengalami digitalisasi. Hal ini dilakukan guna mempertahankan eksistensi media cetak yang mulai tergerus perkembangan zaman. Karena bagaimana pun media cetak memeliki benefit tersendiri, selain murah tetau iklan cetak memiliki sisi nilai seni atau estetika tersendiri dalam menarik minat publik atau pembaca.

\section{Daftar Pustaka}

[1] Gunawan, Imam. 2013. Metode Penelitian Kualitatif: Teori dan Praktik. Jakarta: Bumi Aksara. [2] Merrigan, Gerianne \& Huston, Carole Logan. 2004. Communication Research Methods. USA: Thomson Wadsworth

[3] Sobur, Alex. 2004. Analisis Teks Media. Bandung: PT. Remaja Rosdakarya.

[4] Richard West, Lynn H. Turner. 2008. Pengantar Teori Komunikasi: Analisis dan Aplikasi (Buku 2) Edisi 3. Jakarta: Salemba Humanika 